\title{
Effects of muscle fiber type on glycolytic potential and meat quality traits in different Tibetan pig muscles and their association with glycolysis-related gene expression
}

\author{
L.Y. Shen ${ }^{1}$, J. Luo', H.G. Lei' ${ }^{1}$, Y.Z. Jiang ${ }^{2}$, L. Bai' ${ }^{1}$, M.Z. Li' ${ }^{1}$, G.Q. Tang ${ }^{1}$, X.W. Li' \\ S.H. Zhang ${ }^{1}$ and L. Zhu' ${ }^{1}$ \\ ${ }^{1}$ College of Animal Science and Technology, Sichuan Agricultural University, \\ Chengdu, China \\ ${ }^{2}$ College of Life Science, Sichuan Agricultural University, Chengdu, China \\ Corresponding author: S.H. Zhang \\ E-mail: zhangsh1919@163.com
}

Genet. Mol. Res. 14 (4): 14366-14378 (2015)

Received May 18, 2015

Accepted August 19, 2015

Published November 13, 2015

DOI http://dx.doi.org/10.4238/2015.November.13.22

\begin{abstract}
The myosin heavy chain (MyHC) composition, glycolytic potential, mitochondrial content, and gene expression related to energy metabolism were analyzed in eight muscles from Tibetan pigs, to study how meat quality develops in different muscle tissues. The muscles were classified into three clusters, based on MyHC composition: masseter, trapezius, and latissimus dorsi as 'slow-oxidative-type'; psoas major and semimembranosus as 'intermediate-type'; and longissimus dorsi, obliquus externus abdominis, and semitendinosus as 'fast-glycolytic-type'. The 'slowoxidative-type' muscles had the highest MyHC I and MyHC IIA content $(\mathrm{P}<$ 0.01); 'intermediate-type' muscles, the highest MyHC IIx content $(P<0.01)$; and 'fast-glycolytic-type' muscles, the highest MyHC Ilb content $(P<0.01)$. The $\mathrm{pH}$ values measured in 'slow-oxidative-type' muscles were higher than those in the other clusters were; however, the color of 'fast-glycolytictype' muscles was palest $(P<0.01)$. Mitochondrial content increased in
\end{abstract}


the order: fast-glycolytic-type < intermediate-type < slow-oxidative-type. In the 'slow-oxidative-type' muscles, the expression levels of genes related to ATP synthesis were higher, but were lower for those related to glycogen synthesis and glycolysis. Mitochondrial content was significantly positively correlated with $\mathrm{MyHC}$ I content, but negatively correlated with $\mathrm{MyHC} \mathrm{Ilb}$ content. $\mathrm{MyHC} \mathrm{I}$ and mitochondrial content were both negatively correlated with glycolytic potential. Overall, muscles used frequently in exercise had a higher proportion of type I fibers. 'Slow-oxidative-type' muscles, rich in type I fibers with higher mitochondrial and lower glycogen and glucose contents, had a higher ATP synthesis efficiency and lower glycolytic capacity, which contributed to their superior meat quality.

Key words: Glycolytic potential; Mitochondria; Muscle fiber type; Meat quality; Tibetan pigs

\section{INTRODUCTION}

Pig muscle is converted into pork through the metabolic process of glycolysis, which starts immediately after slaughter. The rate and extent of $\mathrm{pH}$ decline are associated with ultimate meat quality (Hamilton et al., 2003; Ryu and Kim, 2005; Scheffler and Gerrard, 2007). Glycolytic potential (GP) is a measure of all compounds present in the muscle that can be converted into lactate, and is a reliable and rapid predictor of pork quality (Miller et al., 2000; Fontanesi et al., 2008). In the live animal, GP is closely related to the composition of the myosin heavy chain (MyHC) (Klont et al., 1998). For example, Type Ilb fibers have a higher glycogen and glucose content than Type I fibers (Choe et al., 2008), but are less rich in mitochondria than Type I and lla fibers (Staron et al., 1984). Therefore, Type Ilb fibers have a lower oxidative capacity and a higher rate of ATP consumption than Type I fibers (Men et al., 2012). A high GP means that muscles produce a high amount of lactate, which leads to a rapid decrease in $\mathrm{pH}$. Moreover, the denaturation of actin and myosin in the muscle, caused by the decrease in $\mathrm{pH}$, will alter the muscle protein matrix leading to changes in meat color, toughness, and water-holding capacity (Bendall and Swatland, 1988; Lonergan et al., 2007).

In studies on muscle fiber types according to breed, gender, age, and muscle function, Men et al. (2012) found that the proportions of MyHC fiber types I and Ila from selected breeds increased in the order DYL (Duroc $x$ Yorkshire $x$ Landrace crosses) < DZP (Duroc $x$ Zhongbai crosses) $<$ ZBP (Zhongbai pig) < JHP (Jinhua pig), whereas for MyHC Ilb, the order was reversed. Regarding gender, Gutmann et al. (1970) found that the temporalis was a "fast-white" muscle in male guinea pigs, but a "fast-red" muscle in females. Novák et al. (2010) found that the soleus muscle of young rats contained significantly higher MyHC Ila and lower MyHC I levels than that of older rats. Differences in the biological function of muscles, such as workload, also influence the composition of fibers (Staron et al., 1984). Lefaucheur et al. (2004) found that the higher frequency movement of the rhomboideus led to significantly higher MyHC I and lower MyHC Ilb contents than that of the longissimus dorsi, a muscle involving lower levels of exercise. However, there are few reports on meat quality as it varies in different muscles. With improving living standards in many developed countries, the price of pork depends on the cut and the muscles involved. In the present study, eight different skeletal muscles from Tibetan pigs were used to study the effect of muscle fiber type on GP and pork meat quality by analyzing the composition of the muscle fiber, the GP, the mitochondrial content, and their association with the expression of genes related to glycogen synthesis, ATP synthesis, and glycolysis. 


\section{MATERIAL AND METHODS}

The experimental protocol was approved by the Animal Care and Ethics Committee of Sichuan Agricultural University, Sichuan, China, under permit No. DKY-S20093030.

\section{Animals and treatments}

Eight Tibetan pigs ( $60 \pm 3.0 \mathrm{~kg}, 270$ days old) were evaluated. All animals (and carcasses) were subjected to similar treatment and handling along with the whole experiment stage, both feeding and sampling. Just prior to slaughter the pigs were kept off feed, but given free access to water for $24 \mathrm{~h}$, following which they were electrically stunned, exsanguinated, scalded, and rinsed. Samples were obtained from the core of eight muscle tissues: obliquus externus abdominis (OEA); longissimus dorsi (LOD); psoas major (PSM); semimembranosus (SMB); semitendinosus (SMD); masseter (MAS); latissimus dorsi (LAD); and trapezius (TRA). Samples were then rapidly frozen in liquid nitrogen for gene expression and biochemical analysis. At 45 min postmortem, samples were taken from the eight muscles for meat quality measurements. After $24 \mathrm{~h}$ of chilling, additional samples were taken to evaluate and compare meat quality traits.

\section{Meat quality measurements}

Values of muscle $\mathrm{pH}$ were measured with a $\mathrm{pH}$ meter (Orion Research Inc., Boston, MA, USA) at $45 \mathrm{~min}$ and $24 \mathrm{~h}$ postmortem. Color parameters were determined using a Minolta CR-300 colorimeter (Minolta Camera, Osaka, Japan) with an illuminant D65, a $10^{\circ}$ standard observer, and a $2.5 \mathrm{~cm}$ port area. The meat color change values $\left(\Delta \mathrm{E}^{*}\right)$ were calculated as $\Delta \mathrm{E}^{*}=$, where ' $\Delta$ ' means the difference between colors measured at $45 \mathrm{~min}$ and $24 \mathrm{~h}$ postmortem. The $\mathrm{pH}$ change values $\left(\Delta \mathrm{P}^{*}\right)$ were calculated as $\Delta \mathrm{P}^{*}=$, where $\mathrm{pH}_{1}$ and $\mathrm{pH}_{\mathrm{u}}$ represent the $\mathrm{pH}$ values measured at $45 \mathrm{~min}$ and $24 \mathrm{~h}$ postmortem, respectively.

\section{ELISA analysis glycogen, glucose, glucose-6-phosphate, and lactate content}

About 500 mg longissimus dorsi sample was weighed and homogenized in $500 \mathrm{~mL} 0.9 \%$ saline and then centrifuged at $4200 \mathrm{~g}$ for $10 \mathrm{~min}$ at $4^{\circ} \mathrm{C}$. The supernatant was diluted 50 times to measure Gly (Glycogen), Glu (Glucose), G-6-P (Glucose-6-phosphate), and LA (Lactate) content by using standard commercial kits from BlueGene Biotech Co., Ltd. (Shanghai, China), following manufacturer recommendations. Optical density (OD) at $450 \mathrm{~nm}$ was immediately measured utilizing an ELISA microplate reader. A calibration curve was constructed using OD values corresponding to successive concentrations of the standard. Compound contents were expressed as $\mathrm{mmol} / \mathrm{g}$ wet weight and GP values were calculated by the formula: GP $=2 \times($ Gly + Glu + G-6-P) + LA (Monin and Sellier, 1985).

\section{Real-time polymerase chain reaction (PCR) analysis}

The expression levels of selected genes were determined using quantitative reverse transcription polymerase chain reaction (RT-qPCR) analysis. Total RNA was extracted from the longissimus dorsi using the TRIZOL reagent (Invitrogen Corp, Carlsbad, CA) according to manufacturer instructions. Reverse transcription was performed using oligo (dT) random 6-mers 
primers provided in the PrimeScript RT Master Mix kit (TaKaRa, Dalian, China), following manufacturer recommendations. The SYBR Premix Ex Taq kit (TaKaRa, Dalian, China) was used to perform q-PCR on a CFX96 Real-Time PCR detection system (Bio-Rad, Richmond, CA). Primer sequences for q-PCR are shown in Table 1.

\begin{tabular}{|c|c|c|c|}
\hline Gene symbol & Primer sequences ( $\left(5^{\prime}\right.$ to $3^{\prime}$ ) & Amplicon (bp) & $\operatorname{Tm}\left({ }^{\circ} \mathrm{C}\right)$ \\
\hline$A C T B^{*}$ & $\begin{array}{l}\text { TCTGGCACCACACCTTCT } \\
\text { TGATCTGGGTCATCTTCTCAC }\end{array}$ & 114 & 60.0 \\
\hline$T B P^{*}$ & $\begin{array}{l}\text { GATGGACGTTCGGTTTAGG } \\
\text { AGCAGCACAGTACGAGCAA }\end{array}$ & 124 & 60.0 \\
\hline TOP2B* & $\begin{array}{l}\text { AACTGGATGATGCTAATGATGCT } \\
\text { TGGAAAAACTCCGTATCTGTCTC }\end{array}$ & 137 & 60.0 \\
\hline GYG & $\begin{array}{l}\text { CTCTTGTGGCTTCTGTAGAAAGG } \\
\text { AAAGGAATCTGCTCCCATGTAAT }\end{array}$ & 157 & 53.0 \\
\hline GYS1 & $\begin{array}{l}\text { ATGACTCCTCGGACCCTATCTT } \\
\text { TACCCATAACCGTGCATTCAGC }\end{array}$ & 222 & 59.0 \\
\hline PRKAG3 & $\begin{array}{l}\text { CTTGGGCTGGTGGAAGAGAA } \\
\text { CCCACGAAGCTCTGCTTCTT }\end{array}$ & 269 & 60.6 \\
\hline PFK & $\begin{array}{l}\text { GTTGAACGACCTCCAGAAAGC } \\
\text { GGCGGACAACTCAGGAATAAAA }\end{array}$ & 300 & 63.0 \\
\hline$A C L$ & $\begin{array}{l}\text { GAGGCAGCATCGAAACTTCA } \\
\text { TCCCAACTTCTCCCATCACCC }\end{array}$ & 165 & 63.0 \\
\hline PKM & $\begin{array}{l}\text { TTAGCGGCAGCTTTGATAGTTC } \\
\text { CACAATGACCACATCTCCCTTC }\end{array}$ & 264 & 63.0 \\
\hline ATP5A1 & $\begin{array}{l}\text { TAGTAGATGCCCTTGGTAACGC } \\
\text { CCAGTCTGTCGGTCGCCAATAA }\end{array}$ & 202 & 63.0 \\
\hline ATP5B & $\begin{array}{l}\text { GAATCCCTTCTGCGGTGGGTTAT } \\
\text { GGCAGGAGCAGGGTCAGTCAAGT }\end{array}$ & 149 & 60.0 \\
\hline $\operatorname{cox} 1$ & $\begin{array}{l}\text { ACTACTGACAGACCGCAACC } \\
\text { TCCAATGGACATTATGGCTC }\end{array}$ & 147 & 56.0 \\
\hline GCG & $\begin{array}{l}\text { GAATCAACACCATCGGTCAAAT } \\
\text { CTCCACCCATAGAATGCCCAGT }\end{array}$ & 197 & 60.0 \\
\hline HK1 & $\begin{array}{l}\text { GGGTGAGGCTGGTCCGACTTAT } \\
\text { CAGGCGGGTCAGGATTTCTTTT }\end{array}$ & 100 & 59.0 \\
\hline HK2 & $\begin{array}{l}\text { CAAGAGGAGGATGAAGTGGAAA } \\
\text { CACTGGACGATGTGGTCAAAGAG }\end{array}$ & 282 & 63.0 \\
\hline HK4 & $\begin{array}{l}\text { GGCTTCACCTTCTCCTTTCCC } \\
\text { TCTCCGTTTGATGGCATCTCG }\end{array}$ & 138 & 61.0 \\
\hline MyHC1 & $\begin{array}{l}\text { AGCCTCTTTCTTCTCCCAGGGAC } \\
\text { ATCCAGGCTGCGTAACGCTCTT }\end{array}$ & 384 & 55.6 \\
\hline МуHС2a & $\begin{array}{l}\text { CACTTGCTAAGAGGGACCTCTGA } \\
\text { ATCCAGGCTGCGTAACGCTCTTTT }\end{array}$ & 375 & 60.8 \\
\hline $\mathrm{MyHC2b}$ & $\begin{array}{l}\text { CATCTGGTAACATAAGAGGTACA } \\
\text { ATCCAGGCTGCGTAACGCTCTTT }\end{array}$ & 429 & 59.6 \\
\hline MyHC2x & $\begin{array}{l}\text { CTTTCCTCATAAAGCTTCAAGTTC } \\
\text { ATCCAGGCTGCGTAACGCTCTT }\end{array}$ & 398 & 57.5 \\
\hline
\end{tabular}

*Housekeeping gene; Tm, Annealing temperature.

All measurements contained a negative control (without a cDNA template), and each RNA sample was analyzed in triplicate. Fifteen target genes: GYG (glycogenin); GYS1 (glycogen synthase 1); PRKAG3 (protein kinase, AMP-activated, gamma 3 non-catalytic subunit); PFK (Phosphofructokinase); ATP5A1 (ATP synthase, $\mathrm{H}+$ transporting, mitochondrial $\mathrm{F} 1$ complex, alpha subunit 1); ATP5B (ATP synthase, $\mathrm{H}+$ transporting, mitochondrial $\mathrm{F} 1$ complex, beta polypeptide); ACL (ATP-citrate synthase); PKM (pyruvate kinase); HK1 (hexokinase 1); HK2 (hexokinase 2); HK4 (hexokinase 4); MyHC I (myosin heavy chain I); MyHC Ila (myosin heavy chain Ila); MyHC IIx (myosin heavy chain IIx); and MyHC IIb (myosin heavy chain IIb) were normalized to three 
internal control genes ( $A C T B, T B P$, and TOP2B) (Erkens et al., 2006). Relative expression levels of the target mRNAs were calculated using the $\Delta \Delta \mathrm{Ct}$ method (Livak and Schmittgen, 2001). The concentrations of MyHC mRNA were calculated by a standard-curve equation and the ratio of each MyHC mRNA was expressed as $100 \%$ X. The relative copy numbers of mitochondria were designed to be detected by cytochrome oxidase 1 (COX1) and glucagon gene (GCG) for mitochondrial DNA (mtDNA) and nucleic DNA, respectively. The ratio of COX1 to GCG within each sample was used to calculate mtDNA content.

\section{Statistical analysis}

Statistical analysis was performed using ANOVA in the SAS System (SAS 9.2, SAS Inst. Inc., Cary, NC). The model included tissues as the main effects. Duncan's multiple range test was applied to compare the mean values of the tissue samples. Mean values and standard errors are reported in successive Figures. Differences were considered significant if $\mathrm{P} \leq 0.05$. Correlation among different indices was evaluated with Pearson bivariate analysis and a two-tailed test of significance.

\section{RESULTS AND DISCUSSION}

\section{Composition of MyHC in eight muscle tissues from Tibetan pigs}

The composition of MyHC in Tibetan pig muscle tissues is shown in Figure 1A-D.
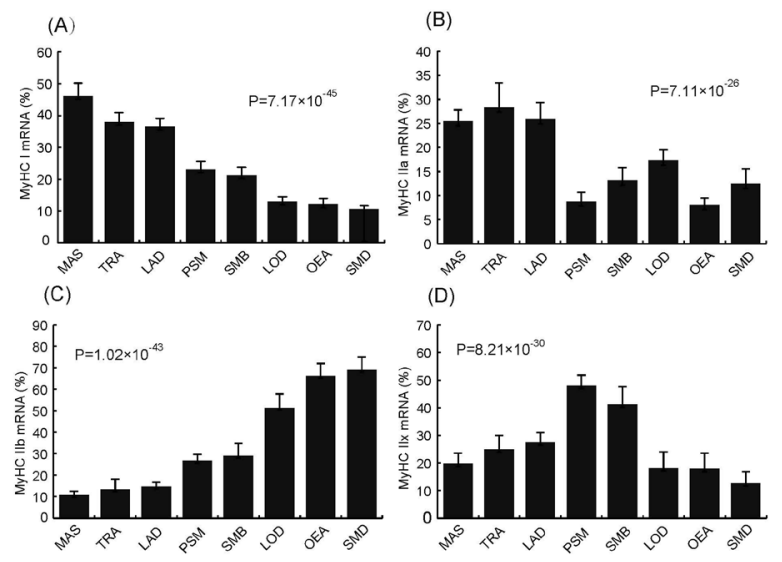

(D)
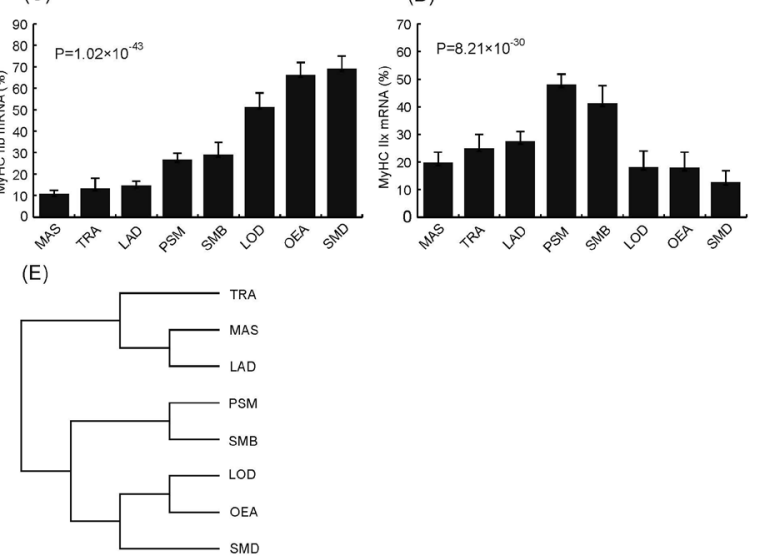

Figure 1. Composition of MyHC mRNA in eight Tibetan pig muscle tissues. A. MyHC I mRNA. B. MyHC Ila mRNA. C. MyHC Ilb mRNA. D. MyHC Ilx mRNA. E. Eight Tibetan pig muscle clustering based on MyHC composition. Data are reported as means \pm SE. MAS: masseter; TRA: trapezius; LAD: latissimus dorsi; PSM: psoas major; SMB: semimembranosus; LOD: longissimus dorsi; OEA: obliquus externus abdominis; and SMD: semitendinosus. 
The masseter, trapezius, and latissimus dorsi muscles had higher $\mathrm{MyHC}$ I and MyHC IIA mRNA concentrations than other muscles $(P<0.01)$ (Figure $1 \mathrm{~A}$ and $1 \mathrm{~B})$. The longissimus dorsi, obliquus externus abdominis, and semitendinosus muscles had higher MyHC Ilb concentrations than other muscles $(P<0.01)$ (Figure $1 C)$. The absolute amounts of MyHC IIx were highest in psoas major and semimembranosus $(P<0.01)$ (Figure $1 D)$. These results are consistent with previous reports. Chang et al. (2003) compared muscle fiber composition in four pig breeds, and found that the longissimus dorsi had higher $\mathrm{MyHC}$ Ilb and lower MyHC Ila, IIx, and I contents than the psoas major. Sazili et al. (2005) also found that the MyHC I content in sheep meat increased in the order: longissimus dorsi < tensor fasciae latae < semitendinosus < supraspinatus < trapezius, but the order for MyHC II fibers was reversed.

Different muscle fiber types have different functions in energy metabolism and contraction: $\mathrm{MyHC} \mathrm{I}$ is a slow contraction, oxidative type, whereas MyHC IIb is a fast contraction, glycolytic type (Schiaffino and Reggiani, 1996). Different muscle tissues are composed of different MyHC subtypes depending on the extent to which they are exercised and their energy requirements. The eight muscle tissues are classified based on MyHC composition in Figure 1E. The muscles clustered as the 'slow-oxidative-type' included the masseter, trapezius, and latissimus dorsi; the 'intermediate-type' included the psoas major and semimembranosus cluster; and the 'fastglycolytic-type' included the longissimus dorsi, obliquus externus abdominis, and semitendinosus cluster. The results are consistent with the function of the muscle tissues; for example, the masseter is the major muscle responsible for chewing food and has the highest amount of movement. The 'slow-oxidative-type' muscle fiber is therefore necessary to provide sufficient energy and persistent contraction without fatigue. In contrast, the 'fast-glycolytic-type' is consistent with the major function of the longissimus dorsi in maintaining body shape, with comparatively less movement. Differences in energy metabolism and muscle contraction could contribute to GP and meat quality. Choe et al. (2008) found that MyHC I content was significantly negatively correlated with GP and positively correlated with ultimate $\mathrm{pH}$ values, but MyHC Ilb showed reverse effects.

\section{Glycolytic potential and meat quality in eight muscles from Tibetan pigs}

As shown in Figure 2, the content of glycogen, G-6-P, glucose, and lactic acid were highest in 'slow-oxidative-type' muscle tissues (Figure 2A, B, C, and D).

There were significant differences in GP between the eight muscle tissues $(P<0.01)$. The average GP in the 'slow-oxidative-type' muscle tissues was lower than that in the 'intermediate-type' tissues $(P<0.05)$, and the average GP in 'intermediate-type' tissues was lower than that in the 'fastglycolytic-type' tissues $(P<0.05)$ (Figure $2 \mathrm{E}$ ). These results are consistent with those of Monin and Sellier (1985), who showed that the longissimus dorsi and semimembranosus muscles had higher GP than the rectus abdominis muscle in Penshire pigs. Choi et al. (2007) found that MyHC Ilb fibers had higher glucose and glycogen contents, and therefore higher GP, than MyHC I fibers.

The measurements of meat quality from the eight muscle tissues are shown in Figure 2F. The $\mathrm{pH}_{1}$ (45 min postmortem) and $\mathrm{pH}_{\mathrm{u}}(24 \mathrm{~h}$ postmortem) values in muscles decreased in the order: 'slow-oxidative-type' > 'intermediate-type' > 'fast glycolytic-type.' However, the meat lightness ( $\left.\mathrm{L}^{*}\right)$ at $45 \mathrm{~min}$ and $24 \mathrm{~h}$ postmortem in 'fast-glycolytic-type' muscles was higher than that in the 'intermediate-type' and 'slow-oxidative-type' $(P<0.05)$. Similar results were reported by Melody et al. (2004), who found that the semimembranosus and psoas major muscles had higher values of $\mathrm{pH}_{\mathrm{u}}$ and water-holding capacity than the longissimus dorsi. Owing to the dissociation of lactate in pork, $\mathrm{pH}$ values decrease with time. With muscle $\mathrm{pH}$ decreasing, sarcoplasmic proteins 
could degenerate and change meat color from red to white. Moreover, the meat protein matrix would be altered, influencing muscle texture and reducing its water holding capacity. Therefore, $\mathrm{pH}$ values are a valuable index to measure complex quantitative traits in meat quality. Muscle fiber characteristics have direct effects on glycolytic potential and meat quality. Ryu and Kim (2005) found that increasing the proportion of MyHC Ilb was related to increasing the postmortem metabolic rate, which caused subsequent deterioration of meat quality.

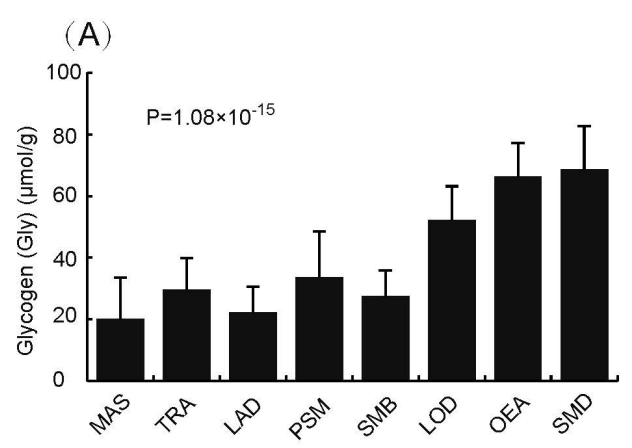

(C)

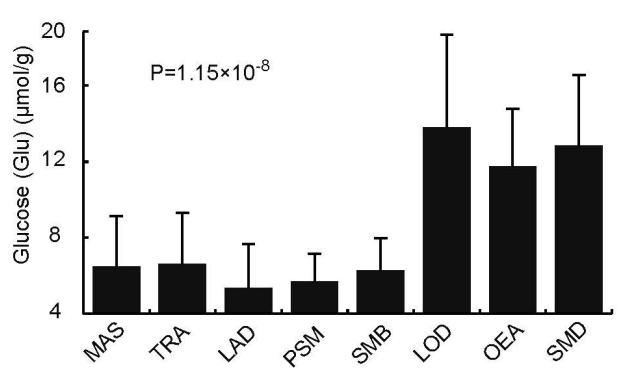

(E)

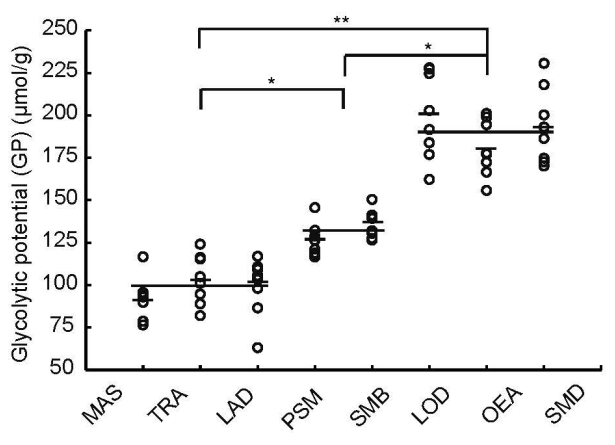

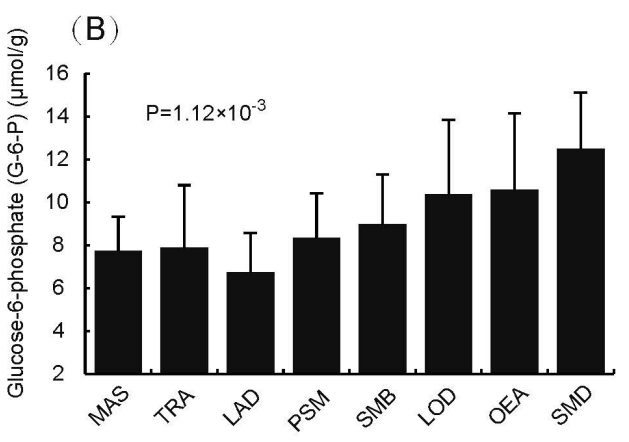

(D)
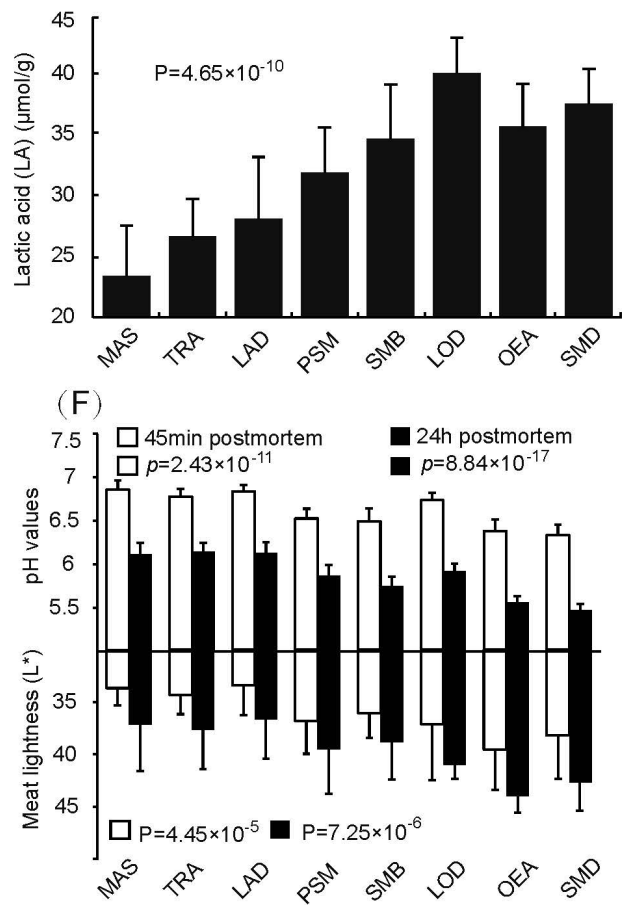

Figure 2. Glycolytic potential and meat quality in eight muscles of the Tibetan pig. A-D: The content of Glycogen (A); G-6-P (B); Glucose (C); and Lactate (D) in the eight muslces of Tibetan pig. (E): Glycolytic potential in eight muscles and average GP of each muscle cluster; short-line represents average of each muscle, long-line represents average of clustering muscles, ${ }^{*} P<0.05,{ }^{* *} P<0.01$. (F): Meat quality of eight Tibetan pig muscles. White columns represent meat quality measured at $45 \mathrm{~min}$ postmortem, black columns represent meat quality measured at $24 \mathrm{~h}$ postmortem. Upper areas of the chart reflect $\mathrm{pH}$ values and lower areas reflect meat lightness $\left(\mathrm{L}^{*}\right)$. 


\section{Mitochondrial content in eight muscles from Tibetan pigs}

Mitochondria constitute the cellular energy factory that plays an important role in postmortem energy metabolism. The mitochondrial DNA copy numbers from each muscle type are shown in Figure 3.

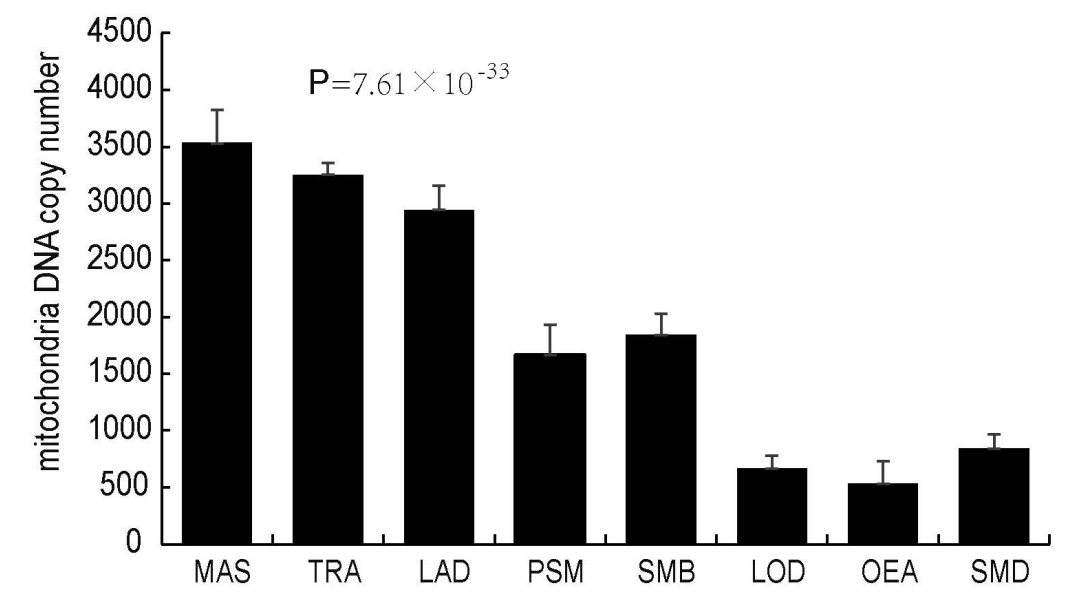

Figure 3. Mitochondrial DNA copy number in each muscle type. Values represent double of the ratio of the amount of mtCOX1 to GCG. Data are reported as means \pm SD.

From our results, it seems that the mitochondrial DNA copy number in the different muscle types increased in the order: 'fast-glycolytic-type' < 'intermediate-type' < 'slow-oxidative-type'. These results are consistent with a previous study (Schwerzmann et al., 1989) that showed the mitochondrial volume density in muscle fibers was higher in the 'oxidative' soleus muscle than in the 'glycolytic' gracilis muscle.

The mitochondrial DNA copy number has different distributions according to muscle fiber type (Ingjer, 1979). Arany et al. (2007) found that MyHC I and Ila fibers were more oxidative and rich in mitochondria than Ilb fibers. Mitochondrial DNA copy number has been found to be closely related to muscle energy metabolic status (Zong et al., 2002), which depends on the level of exercise of the muscle (Irrcher et al., 2003). Some interesting findings about the influence of exercise on mitochondrial content (Irrcher et al., 2003; Yan et al., 2011), showed that endurance exercise could induce $\mathrm{MyHC} \mathrm{Ilb}$ change to $\mathrm{MyHC} \mathrm{I}$, and thereby increase mitochondrial content. Therefore, in the present study the masseter muscle, having the highest mitochondrial content, was also associated with the highest exercise frequency in chewing food daily. Moreover, pyruvic acid can be broken down into lactate through glycolysis, or be transferred into mitochondria to produce $\mathrm{CO}_{2}$ and water through oxidation. Therefore, to some extent, the density of mitochondria in muscle fibers determines energy metabolic type.

\section{Correlations between muscle fiber type, mitochondrial content, GP, and meat quality traits}

The correlations between muscle fiber type and mitochondrial content, and GP and meat quality traits are shown in Table 2. 
Table 2. Coefficients of correlation among MyHC mRNA composition, mitochondrial content, GP, and meat quality traits.

\begin{tabular}{|c|c|c|c|c|c|c|c|c|}
\hline Traits & MyHC1 & MyHC2a & MyHC2b & $\mathrm{MyHC} 2 \mathrm{x}$ & Glycogen & Glucose & LA & GP \\
\hline MtDNA & $0.31^{* *}$ & 0.08 & $-0.27^{\star \star}$ & $0.12^{\star}$ & $-0.25^{\star}$ & $-0.22^{*}$ & $-0.18^{*}$ & $-0.26^{\text {** }}$ \\
\hline Glycogen & $-0.39^{* *}$ & $-0.21^{*}$ & $0.43^{\star \star \star}$ & -0.15 & 1 & $0.33^{* *}$ & $0.14^{*}$ & $0.38^{\text {** }}$ \\
\hline Glucose & $-0.26^{\star *}$ & $-0.13^{*}$ & $0.34^{\star *}$ & -0.08 & $0.36^{\star \star}$ & 1 & $0.17^{\star}$ & $0.27^{\star *}$ \\
\hline LA & $-0.23^{*}$ & -0.07 & $0.20^{\star *}$ & -0.04 & $0.25^{\star \star}$ & $0.26^{*}$ & 1 & $0.18^{* *}$ \\
\hline GP & $-0.47^{\star \star \star}$ & $-0.16^{*}$ & $0.33^{\star *}$ & $-0.11^{*}$ & $0.40^{\star *}$ & $0.38^{\star \star}$ & $0.12^{*}$ & 1 \\
\hline $\mathrm{pH}_{1}$ & $0.12^{*}$ & 0.08 & $-0.23^{\text {** }}$ & -0.10 & $-0.23^{\star *}$ & $-0.13^{*}$ & -0.08 & $-0.24^{* *}$ \\
\hline $\mathrm{pH}_{\mathrm{u}}$ & $0.29^{\star *}$ & $0.15^{*}$ & $-0.19^{\star *}$ & 0.08 & $-0.29^{\star \star}$ & $-0.27^{\star \star}$ & $-0.13^{*}$ & $-0.32^{\star *}$ \\
\hline$\Delta \mathrm{P}^{\mathrm{u}}$ & -0.06 & 0.07 & $0.16^{*}$ & -0.04 & $0.18^{\star}$ & $0.16^{\star}$ & 0.06 & $0.17^{\star}$ \\
\hline$L^{*}{ }_{1}$ & $-0.19^{\star *}$ & -0.05 & $0.23^{*}$ & -0.13 & $0.25^{*}$ & $0.21^{\star *}$ & 0.12 & $0.26^{*}$ \\
\hline$L^{*}{ }_{u}^{1}$ & $-0.21^{\star *}$ & $-0.16^{*}$ & $0.18^{\star *}$ & -0.05 & $0.18^{\star \star}$ & $0.18^{*}$ & 0.03 & $0.22^{*}$ \\
\hline$\Delta \mathrm{E}$ & -0.05 & 0.03 & $0.14^{*}$ & -0.16 & $0.11^{*}$ & 0.10 & -0.08 & $0.12^{*}$ \\
\hline
\end{tabular}

MtDNA, Mitochondrial DNA copy number; LA, Lactate content; GP, glycolytic potential; $\mathrm{pH}_{1}$, measured at 45 min postmortem; $\mathrm{pH}_{\mathrm{u}}$, measured at $24 \mathrm{~h}$ postmortem; $\Delta \mathrm{P}, \mathrm{pH}$ value change at $45 \mathrm{~min}$ and $24 \mathrm{~h}$ postmortem; $\mathrm{L}^{*}$, meat lightness measured at 45 min postmortem; $L^{*}$, meat lightness measured at $24 \mathrm{~h}$ postmortem; $\Delta \mathrm{E}$, meat lightness change at $45 \mathrm{~min}$ and $24 \mathrm{~h}$ postmortem. ${ }^{*} \mathrm{P}<0.05,{ }^{* *} \mathrm{P}<0.01,{ }^{* * *} \mathrm{P}<0.001$.

The MyHC I content had a strong negative correlation with GP $(r=-0.47, \mathrm{P}<0.001)$ and glycogen $(r=-0.39, \mathrm{P}<0.01)$. The MyHC Ilb content had a strong positive correlation with glycogen $(r=0.43, \mathrm{P}<0.001)$, glucose $(r=0.34, \mathrm{P}<0.01)$, GP $(r=0.33, \mathrm{P}<0.01)$, and $\mathrm{L}_{1}^{*}(r=0.23, \mathrm{P}<$ 0.05). However, the MyHC Ila and MyHC IIx contents were not strongly correlated with GP nor with meat quality. Moreover, mitochondrial content was positively correlated with $\mathrm{MyHC}$ I and $\mathrm{MyHC} \mathrm{IIx}$ contents ( $r=0.31, \mathrm{P}<0.01 ; r=0.12, \mathrm{P}<0.05$, respectively) and negatively correlated with MyHC Ilb content $(r=-0.27, \mathrm{P}<0.01)$. Interestingly, the mitochondrial content was also significantly correlated with glycogen, glucose, lactate, and GP ( $<<0.01)$. Similar relationships reported by other studies (Chang et al., 2003; Hamilton et al., 2003; Hambrecht et al., 2005; Lefaucheur, 2006) have indicated that as the MyHC Ilb content increased within muscle, the glycogen content and GP also increased, but meat quality decreased. These researchers also demonstrated that the variation in meat quality was caused by postmortem energy metabolism related to mitochondria that generate the ATP supply for every biological function. However, there is an apparent lack of reports about the relationship between mitochondrial content and GP, or meat quality. From our results, it can be inferred that the variation in meat quality from different muscle tissues, might be caused by differences in the proportions of muscle fiber types and in the mitochondrial content. For example, the comparatively high mitochondrial content in Type I fibers could suggest greater availability of pyruvic acid to generate ATP through the tricarboxylic acid cycle in mitochondria. Therefore, Type I fibers would have had less pyruvic acid to produce lactate through anaerobic glycolysis in cytoplasm.

\section{Metabolism-related gene expression in eight muscle tissues from Tibetan pigs}

As shown in Figure $4 \mathrm{~A}-\mathrm{K}$, the expression of metabolic-related genes showed differences between the eight muscle tissues.

The mRNA levels of the two genes encoding glycogenin (GYG) and glycogen synthase (GYS1) were significantly higher in 'fast-glycolytic-type' muscles than in 'intermediate-type' and 'slow-oxidative-type' muscles $(\mathrm{P}<0.01)$ (Figure 4A and $\mathrm{B})$. The mRNA levels of the ACLY, ATP5B, and ATP5A1 genes for ATP synthesis were significantly higher in 'slow-oxidative-type' muscles than in 'intermediate-type' and 'fast glycolytic-type' muscles $(P<0.01)$ (Figure 4C, D, and E). 
The mRNA levels of the four genes HK1, HK2, HK4, and PFK encoding rate-limiting enzymes in glycolysis were significantly lower in 'slow-oxidative-type' muscles than in 'intermediate-type' and 'fast-glycolytic-type' muscles $(\mathrm{P}<0.01)$ (Figure $4 \mathrm{~F}, \mathrm{G}, \mathrm{H}$, and I). The mRNA levels of the PRKAG3 gene, which responds to cellular metabolic stresses, was higher in 'fast-glycolytic-type' than in 'slow-oxidative-type' muscles $(P<0.01)$ (Figure $4 \mathrm{~J})$. However, the mRNA levels for gene-encoding pyruvate kinase showed no significant differences among the eight muscle tissues $(P>0.05)$ (Figure $4 \mathrm{~K}$ ). The expression patterns of the 11 genes (Figure 4L) showed that those for ACLY, $A T P 5 B$, and ATP5A1 differed from the others.
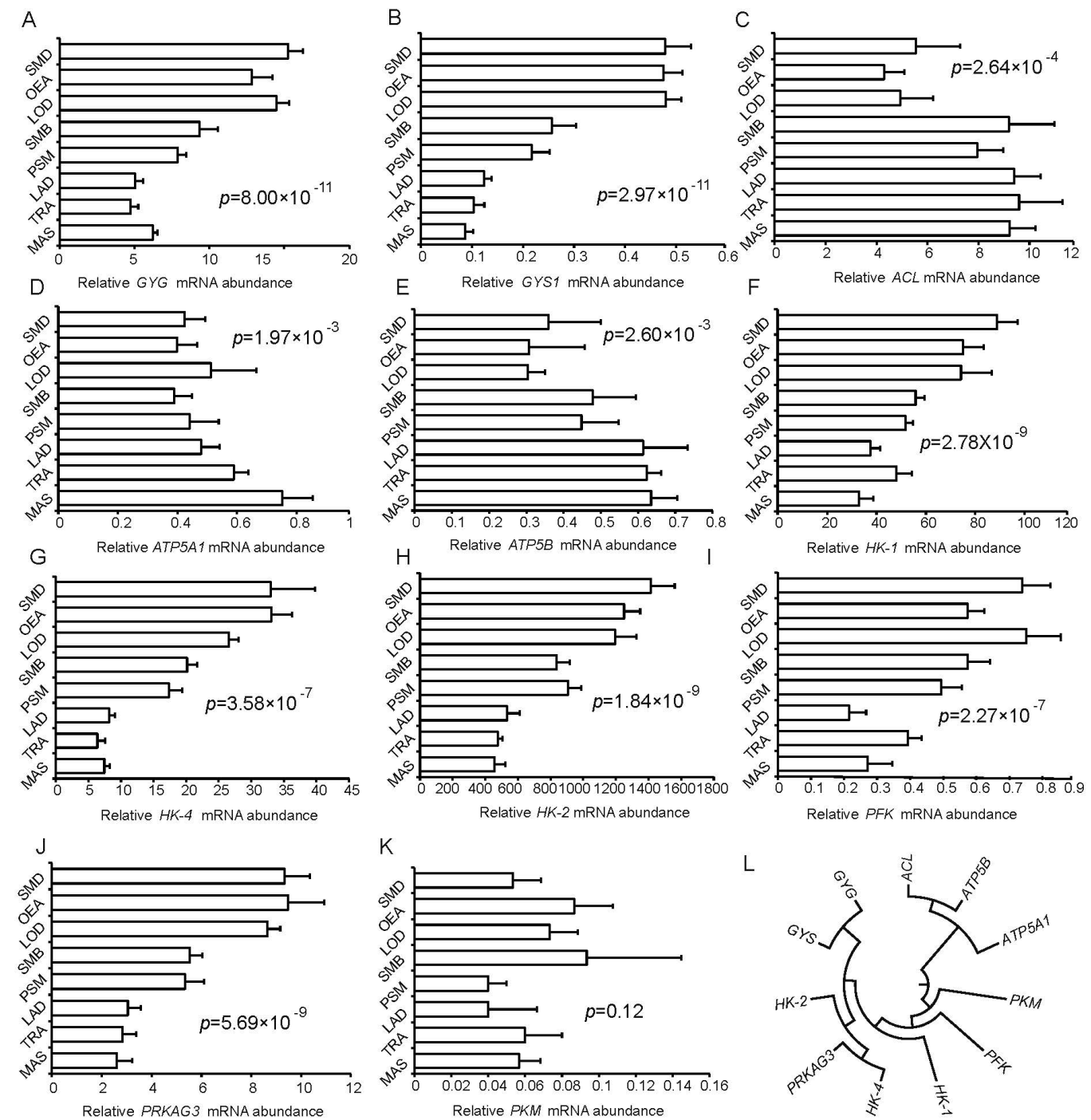

$\mathrm{K}$

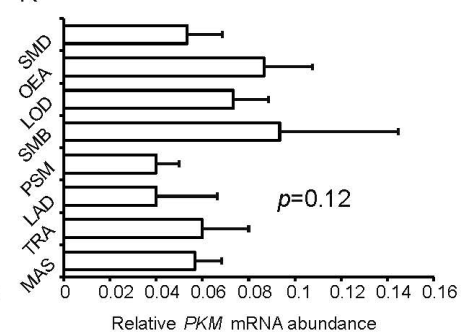

L

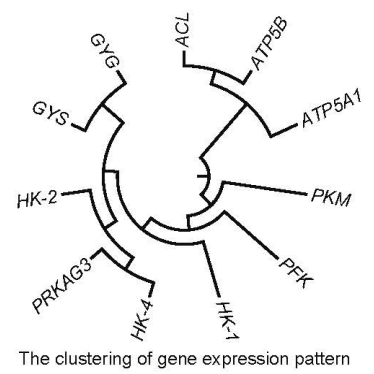

Figure 4. Metabolism-related gene expression in eight muscle tissues of Tibetan pigs. A-K: The genes GYG, GYS1, ACL, ATP5A1, ATP5B, HK-1, HK-2, HK-4, PFK, PRKAG3, and PKM expression in eight muscles. Relative quantification used ACTB, TBP, and TOP2B, three internal control genes to normalize. L: Clustering of gene expression patterns. 
According to these expression patterns, the high levels of GYG, GYS1, HK1, HK2, HK4, and PFK mRNA in 'fast-glycolytic-type' muscles suggested that they had a higher glycogen content and rate of glycolysis. The glycogen synthase complex was composed of GYG (glycogenin) and GYS1 (glycogen synthase) proteins, which must both be present for the glycogen synthesis reaction. Sukigara et al. (2012) and McCue et al. (2008) found that mutation of the GYS1 and GYG genes could cause serious diseases in humans, based on defects in muscle glycogen storage. Hexokinase (HK) is an important rate-limiting enzyme that catalyzes the reaction for the degradation of glycogen through glycolysis, and thus influences pork quality. Different types of $\mathrm{HK}$ isozymes exist in different tissues: HK-1 is the predominant isozyme in brain, HK-2 is mainly found in muscle tissues, and HK-4 is mainly found in hepatocytes and pancreatic islets. All three isozymes are adapted to facilitate glucose phosphorylation in different types of cell (Steinke et al., 2006). The results of the present study show that $H K-2$ was the predominantly expressed mRNA in muscle tissues. This might be due to the high-altitude, hypoxic living conditions of the Tibetan pigs used. Gwak et al. (2005) found that hypoxia could stimulate the proliferation of human hepatoma cells through the induction of hexokinase II expression. PFK catalyzes the conversion of fructose 1-phosphate and ATP to fructose 1,6-bisphosphate and ADP, and according to our results, there was a correlation between PFK mRNA expression and GP. Pyruvate kinase (PKM) catalyzes the irreversible conversion of phosphoenolpyruvate and ADP to pyruvate and ATP. However, the related mRNA expression levels showed no significant differences among the eight muscle tissues studied, which supports the gene expression patterns in Figure 4L. Interestingly, Allison et al. (2003) found that pyruvate kinase capacity was not correlated with longissimus $\mathrm{pH}$ values and drip loss. Therefore, the expression level of PFK cannot readily explain the differences in glycolysis rates. Our findings revealed that the biceps femoris and longissimus dorsi muscles had higher glycogen and lactate contents, and GP but inferior meat quality compared to other muscle tissues. According to the expression of ACLY, ATP5B, and ATP5A1 genes, we can conclude that the efficiency of producing ATP in 'slow-oxidative-type' muscles was higher than that in 'fastglycolytic-type' type muscles. Although there are different metabolic types in muscle, concerning oxidative and glycolytic metabolism, the process of glycogen or glucose conversion to pyruvic acid was the same for both oxidative and anaerobic metabolism. However, pyruvic acid can be broken down into lactate through glycolysis, or can be transferred into mitochondria to produce $\mathrm{CO}_{2}$ and water through oxidation. The anaerobic metabolism of glucose is inefficient and produces only two ATP molecules for each glucose molecule, whereas complete oxidative metabolism produces 38 ATP molecules (Gatenby and Gillies, 2004). Therefore, 'fast-glycolytic-type' muscles with a lower mitochondrial content need more glucose and glycogen molecules as raw materials for glycolysis, to satisfy the demand for ATP to allow tissues to maintain normal functions. Thus, the mitochondrial content has a major influence on the variation of meat quality in different muscle tissues.

\section{CONCLUSION}

Our results suggest that 'slow-oxidative-type' muscles, with generally higher levels of activity, have higher MyHC I and lower MyHC Ilb contents than 'intermediate-type' and 'fastglycolytic-type' muscles with lower levels of activity. The MyHC I content of muscles was positively correlated, and the $\mathrm{MyHC} \mathrm{llb}$ content was negatively correlated with mitochondrial content. Muscles with higher mitochondrial content (e.g. the masseter) were highly efficient in ATP synthesis and thus needed less glycogen and glucose for glycolysis, to provide energy. The relatively high levels of mRNA expression for genes related to glycogen synthesis (GYG and GYS), and genes related 
to glycolysis (HK1, HK2, HK4, and PFK) contributed to the high glycogen content, glycolytic rate, and GP in 'fast-glycolytic-type' muscles. Our results provide more information exploring the effect of mitochondrial content in muscle fibers on pork quality.

\section{Conflicts of interest}

The authors declare no conflict of interest.

\section{ACKNOWLEDGMENTS}

The study was supported by the Initiation Foundation Project of the Chinese Education Ministry, the earmarked fund for China Agriculture Research System (\#CARS-36-05B), and the Sichuan Sci \& Tech Support Program (\#2012NZ001 and 2011NZ0034).

\section{REFERENCES}

Allison CP, Bates RQ, Booren AM, Johnson RC, et al. (2003). Pork quality variation is not explained by glycolytic enzyme capacity. Meat Sci. 63: 17-22.

Arany Z, Lebrasseur N, Morris C, Smith E, et al. (2007). The transcriptional coactivator PGC-1 $\beta$ drives the formation of oxidative type IIX fibers in skeletal muscle. Cell Metab. 5: 35-46.

Bendall JR and Swatland HJ (1988). A review of the relationships of pH with physical aspects of pork quality. Meat Sci. 24: 85-126.

Chang KC, da Costa N, Blackley R, Southwood O, et al. (2003). Relationships of myosin heavy chain fibre types to meat quality traits in traditional and modern pigs. Meat Sci. 64: 93-103.

Choe JH, Choi YM, Lee SH, Shin HG, et al. (2008). The relation between glycogen, lactate content and muscle fiber type composition, and their influence on postmortem glycolytic rate and pork quality. Meat Sci. 80: 355-362.

Choi YM, Ryu YC and Kim BC (2007). Influence of myosin heavy- and light chain isoforms on early postmortem glycolytic rate and pork quality. Meat Sci. 76: 281-288.

Erkens T, Van Poucke M, Vandesompele J, Goossens K, et al. (2006). Development of a new set of reference genes for normalization of real-time RT-PCR data of porcine backfat and longissimus dorsi muscle, and evaluation with PPARGC1A. BMC Biotechnol. 6: 41.

Fontanesi L, Davoli R, Nanni Costa L, Beretti F, et al. (2008). Investigation of candidate genes for glycolytic potential of porcine skeletal muscle: Association with meat quality and production traits in Italian Large White pigs. Meat Sci. 80: 780-787.

Gatenby RA and Gillies RJ (2004). Why do cancers have high aerobic glycolysis? Nat. Rev. Cancer 4: 891-899.

Gutmann E, Hanzlíková V and Lojda Z (1970). Effect of androgens on histochemical fibre type. Histochemie 24: 287-291.

Gwak GY, Yoon JH, Kim KM, Lee HS, et al. (2005). Hypoxia stimulates proliferation of human hepatoma cells through the induction of hexokinase II expression. J. Hepatol. 42: 358-364.

Hambrecht E, Eissen JJ, Newman DJ, Smits CH, et al. (2005). Preslaughter handling effects on pork quality and glycolytic potential in two muscles differing in fiber type composition. J. Anim. Sci. 83: 900-907.

Hamilton DN, Miller KD, Ellis M, McKeith FK, et al. (2003). Relationships between longissimus glycolytic potential and swine growth performance, carcass traits, and pork quality. J. Anim. Sci. 81: 2206-2212.

Ingjer $F$ (1979). Capillary supply and mitochondrial content of different skeletal muscle fiber types in untrained and endurancetrained men. A histochemical and ultrastructural study. Eur. J. Appl. Physiol. Occup. Physiol. 40: 197-209.

Irrcher I, Adhihetty PJ, Joseph AM, Ljubicic V, et al. (2003). Regulation of mitochondrial biogenesis in muscle by endurance exercise. Sports Med. 33: 783-793.

Klont RE, Brocks L and Eikelenboom G (1998). Muscle fibre type and meat quality. Meat Sci. 49S1: S219-S229.

Lefaucheur L (2006). Myofibre typing and its relationships to growth performance and meat quality. Arch. Tierzucht, Dummerstorf 49: 4-17.

Lefaucheur L, Milan D, Ecolan P and Le Callennec C (2004). Myosin heavy chain composition of different skeletal muscles in Large White and Meishan pigs. J. Anim. Sci. 82: 1931-1941.

Livak KJ and Schmittgen TD (2001). Analysis of relative gene expression data using real-time quantitative PCR and the $2^{-\triangle \Delta C T}$ Method. Methods. 25: 402-408. 
Lonergan SM, Stalder KJ, Huff-Lonergan E, Knight TJ, et al. (2007). Influence of lipid content on pork sensory quality within pH classification. J. Anim. Sci. 85: 1074-1079.

McCue ME, Valberg SJ, Miller MB, Wade C, et al. (2008). Glycogen synthase (GYS1) mutation causes a novel skeletal muscle glycogenosis. Genomics 91: 458-466.

Melody JL, Lonergan SM, Rowe LJ, Huiatt TW, et al. (2004). Early postmortem biochemical factors influence tenderness and water-holding capacity of three porcine muscles. J. Anim. Sci. 82: 1195-1205.

Men XM, Deng B, Xu ZW and Tao X (2012). Muscle-fibre types in porcine longissimus muscle of different genotypes and their association with the status of energy metabolism. Animal Prod. Sci. 52: 305-312.

Miller KD, Ellis M, Bidner B, McKeith FK, et al. (2000). Porcine Longissimus glycolytic potential level effects on growth performance, carcass, and meat quality characteristics. J. Muscle Foods 11: 169-181.

Monin G and Sellier P (1985). Pork of low technological quality with a normal rate of muscle pH fall in the immediate postmortem period: The case of the Hampshire breed. Meat Sci. 13: 49-63.

Novák P, Zacharová G and Soukup T (2010). Individual, age and sex differences in fiber type composition of slow and fast muscles of adult Lewis rats: comparison with other rat strains. Physiol. Res. 59: 783-801.

Ryu YC and Kim BC (2005). The relationship between muscle fiber characteristics, postmortem metabolic rate, and meat quality of pig longissimus dorsi muscle. Meat. Sci. 71: 351-357.

Sazili AQ, Parr T, Sensky PL, Jones SW, et al. (2005). The relationship between slow and fast myosin heavy chain content, calpastatin and meat tenderness in different ovine skeletal muscles. Meat. Sci. 69: 17-25.

Scheffler TL and Gerrard DE (2007). Mechanisms controlling pork quality development: The biochemistry controlling postmortem energy metabolism. Meat. Sci. 77: 7-16.

Schiaffino S and Reggiani C (1996). Molecular diversity of myofibrillar proteins: gene regulation and functional significance. Physiol. Rev. 76: 371-423.

Schwerzmann K, Hoppeler H, Kayar SR and Weibel ER (1989). Oxidative capacity of muscle and mitochondria: correlation of physiological, biochemical, and morphometric characteristics. Proc. Natl. Acad. Sci. U.S.A. 86: 1583-1587.

Staron RS, Hikida RS, Hagerman FC, Dudley GA, et al. (1984). Human skeletal muscle fiber type adaptability to various workloads. J. Histochem. Cytochem. 32: 146-152.

Steinke D, Hoegg S, Brinkmann H and Meyer A (2006). Three rounds (1R/2R/3R) of genome duplications and the evolution of the glycolytic pathway in vertebrates. BMC Biol. 4: 16.

Sukigara S, Liang WC, Komaki H, Fukuda T, et al. (2012). Muscle glycogen storage disease 0 presenting recurrent syncope with weakness and myalgia. Neuromuscul. Disord. 22: 162-165.

Yan Z, Okutsu M, Akhtar YN and Lira VA (2011). Regulation of exercise-induced fiber type transformation, mitochondrial biogenesis, and angiogenesis in skeletal muscle. J. Appl. Physiol. 110: 264-274.

Zong H, Ren JM, Young LH, Pypaert M, et al. (2002). AMP kinase is required for mitochondrial biogenesis in skeletal muscle in response to chronic energy deprivation. Proc. Natl. Acad. Sci. U.S.A. 99: 15983-15987. 